\title{
Taking active learning into the primary school: a matter of new practices?
}

\begin{abstract}
This paper examines the extension of active learning pedagogical practices familiar in preschool settings to the first class of primary school. Policy and practice guidance in the UK is advocating the benefits of experiential learning as a way of engaging young children as they move into primary school but for teachers this means a move to new practices which can be in tension with other expectations. In this paper the rationale for active learning is considered along with an account of the classroom activities of teachers and children in five primary settings implementing the policy shift to active learning. The children in these classes spent varying amounts of time in whole class activities led by the teacher or in small groups directed to engage with specific activities. They had opportunities to engage and respond verbally, through manipulating objects and with physical actions but the emphasis was on planned, teacher-directed learning activities. The characteristics of active learning as introduced in these innovative classes are compared with the expectations of practice guidance and theorising about early learning.
\end{abstract}

Key words: Active learning; primary school; classroom practices; teacher actions; implementing policy

\section{Introduction}

Two recent reviews of primary school education in Britain have suggested that active, interactive and collaborative learning experiences would be of benefit beyond the preschool years (Rose Report, DCSF, 2009; Cambridge Primary Review, Alexander, 2009). They argue that the educational experiences that children have as they begin primary school should capitalize on their appetite for learning and practical activities and avoid denting early confidence and enthusiasm. In Wales the Foundation Stage already recommends a focus on 'play/active learning' and 'active educational play' for children aged 3 to 7 years old (Welsh Assembly Government, 2008 p.7). In Scotland re-structuring of the national curriculum has created an Early Level which encompasses the two years of part-time preschool education available to all children along with the first year of primary school (Learning and Teaching Scotland, 2009a). The practice guidance for this Early Level directs teachers responsible for the first class in primary school (P1) to adopt an 'active learning' pedagogy.

Across the UK there is an explicit expectation in policy and practice guidance (e.g. DCSF, 2007; Northern Ireland Curriculum, 2009) that adult-supported, experiential learning should be the dominant mode for children in their preschool years, a position endorsed by the findings of the Effective Provision of Preschool Education (EPPE) study and the associated investigation of effective pedagogy (Siraj-Blatchford \& Sylva, 2004). But the move to school has typically meant a move to a more formal and traditional 'transmission-oriented' approach to learning which demands that children are ready to engage in particular ways if they are to succeed (Stephen \& Cope, 2003). Although some early years or infant classes have always incorporated time for less formal educational experiences such as 'structured play' or time for children to use play resources when other tasks had been completed, moving to a predominantly active learning pedagogy is likely to be perceived as challenging for 
teachers and require a change in the ways in which they think about the processes that support learning, the learning environment and their own role (Bennett, Wood \& Rogers, 1997).

This paper explores the challenges and benefits experienced when an experiential approach to learning is extended from preschool settings to the first class in primary school (P1). It draws on empirical evidence from a study in Scotland of the implementation of the policy imperative to move to active learning throughout the Early Level (3-6 years). The paper begins by examining the rationale for active learning, looking at policy expectations and foundations in theory. We move on to present evidence about the experience of implementing active learning in five classrooms observed as examples of innovative practice, before concluding with a discussion of the pedagogical actions and interactions observed and the challenges encountered in moving from policy to practice.

\section{The rationale for active learning: perspectives from policy and theory}

Constructing children as actively contributing to and shaping their own learning, and constructing knowledge through actions and interactions with adults and peers, is characteristic of much of preschool thinking about learning. The value of what is variously expressed as experiential learning, learning through play, exploration or activities has long been championed in the advice on good practice for nursery settings and it is deeply embedded in the powerful consensual, and often implicit, expectations about preschool practice in the UK. Indeed, the origins of the emphasis on the value of immediate, direct experience and children making their own choices about which activities to engage with can be traced to ideas advocated by pioneers such as Isaacs (1932) and Montessori (1966). Experiential learning is a key characteristic of the Developmentally Appropriate Practice approach (Bredekamp and Copple, 1997). Originally articulated in the USA, this approach has been influential in the formulation of educational provision for 3- to 5-year olds in the UK (Siraj-Blatchford, 1999). The High/Scope programme which is widely used in the USA, particularly in settings for disadvantaged children, also advocates what it describes as active learning, arguing that children reach new understandings through direct actions on objects, interactions with other people and ideas, and reflecting on their actions (Hohmann and Weikart, 1995).

The guidance and wealth of advice available to teachers in the UK (e.g. Teachernet, 2007; Learning and Teaching Scotland, 2009b) suggests that active learning means offering opportunities for children to be involved in play and activities which they find engaging and which support and prompt learning. In the primary school active learning is often presented as moving away from passive listening and replacing worksheets with activities such as counting and adding with model animals, actions, songs and art work to rehearse phonics or problem-solving in a construction project. More specifically, in Scotland the curriculum requirements for the classes included in this study describe active learning as 'learning which engages and challenges children's thinking using real-life and imaginary situations' (Scottish Executive, 2007). The guidance goes on to list spontaneous play, planned and purposeful play, investigating and exploring, events and real life experiences and focused learning and teaching as all contributing to this process. Furthermore, it calls for a wide range of resources to be available, space for children to learn through 'social, sensory, creative, constructive and dramatic activities' and for learning opportunities to be appropriately paced and challenging in order to meet the needs of individuals. Teachers are asked to plan responsively and intervene with sensitivity. However, there remain expectations of and targets for the acquisition of specific knowledge and 
skills (e.g. for reading and numeracy) within school and local authority accountability systems.

The two theories of learning that have dominated thinking in the early years literature and in the professional education of teachers - the work of Piaget and Vygotsky - can both be interpreted as offering support for an active learning pedagogy, or at least drawing attention to features of the learning process that require active engagement with the environment and the people in it. The Piagetian legacy places 'the dynamic and continuing interaction of child and environment' as central to the learning of young children (Schaffer 2004, p. 164). Despite the substantial challenges to Piaget's linear conception of development (e.g. Donaldson, 1978), the value of a richly resourced learning environment and time to explore and reflect on what is new, different or challenging has an enduring influence on expectations about appropriate practice in preschool settings (Fleer et al, 2009). At the core of socio-cultural understandings of the acquisition and development of situated knowledge and skills is the mediation of learning through engagement with particular resources, actions and actors that are culturally meaningful (e.g. Rogoff, 2003; Wertsch,1998; Vygotsky, 2004). Theorising from a Vygotskian perspective, Hedegaard \& Fleer (2008) argue that development is the result of the dynamic interaction of children's motives, the activities which are part of the traditional practices in the cultural-material setting they experience and the activities which the young learners generate for themselves.

Other recent theorising has elaborated on the process of knowledge construction: developing understandings of the creative and questioning processes or encounters that constitute learning. Olsson (2009) conceptualises learning as a process of new compositions or assemblages that happen as children engage with problems and experiences from their own perspectives. For her learning is what goes on as children tackle problems rather than achieve specified outcomes. Thought of in this way, active engagement with a project or problem is the core of learning. However, it is always open and unpredictable. It requires teachers to be well prepared and knowledgeable but also ready to be surprised, to 'let go', and to respond sensitively. Taguchi (2010) also argues for attention to what happens as children engage with others and with the material world. She sees learning as emerging and evolving through the intra-actions between the child, the physical world and resources and the people and ideas they encounter. Challenging notions of an external 'knowable' world, Taguchi's thinking suggests a pedagogy that attends to action and performance as well as language and cognition and which provokes, values and extends individual sense-making. Supporting learning in this way demands pedagogical actions and documentation that focus on plurality and collaborative invention.

The Scottish policy documents (Scottish Executive, 2007) which advocate active learning do not attempt to theorise it or make explicit the tensions that are inherent in alternative models of learning. There is a reference to a review of the literature on early years education (Stephen, 2006) as supporting the development of the 'active learning' policy but there are no links to specific evidence. The focus is on what is claimed to be a worldwide consensus that active learning is an appropriate pedagogy, advocating the particular practices outlined above and valorising play and adult responsiveness to children.

\section{Observing active learning in practice}

\section{Study methods}


In this paper we draw on empirical evidence from a small-scale, exploratory study to inform the debate about putting active learning into practice (Stephen, Ellis and Martlew, 2009). The aim of that study was to investigate how active learning was being construed and put into practice. Systematic observations of the actions of teachers and of the children in the classroom were conducted to allow us to address the research question: What form does active learning take in Scottish P1 classrooms?

We asked two local authorities known to have adopted a proactive position towards active learning in the early years of their primary schools to nominate teachers to take part in the study. The evidence reported in this paper comes from five teachers in four primary schools (two teachers took part at one large primary school). These teachers were seen by their managers as effective champions for the development of active learning. We observed each class for half a day on four occasions over one year, during October, December, March and June.

During each visit we noted the physical resources available to the class teacher and the learning materials that were available during the observation session. We utilised two observation techniques on each occasion (i) scans of the whole classroom at regular time intervals and (ii) timed observations of target children in each setting. Scans of the classroom were carried out at 10-minute intervals throughout each observation period. At each scan we noted: how the children were grouped; what they were doing and the actions of the teacher or other adults in the room. For the target child observations we selected children randomly in each setting, but were careful to balance the number of boys and girls. We completed three rounds of observations per visit for each target child. Each of these rounds lasted for approximately five minutes during which the researcher noted: what the child was doing, who was with her/him; interactions with other children or adults; behavioural indicators of pleasure or satisfaction and the level of the child's engagement (intensely engaged, engaged, intermittent engagement, passive, not engaged).

The research team trained together to establish shared understandings of the categories used to code observations and for the analysis. Judgements about engagement are relatively high inference but were made on the basis of observable bodily indications such as eye contact with a speaker, turning away or fidgeting, being alert or sleepy (Stephen, 2003). We categorised the actions of the teachers and children and identified the most frequently observed behaviours of adults and learners when the class was gathered as a whole group and when they were distributed in small groups over a range of learning activities. The study was subject to scrutiny by a university department ethics committee. The research team took care to establish the informed consent of the adults who took part and the assent of children, treating consent and assent as subject to review throughout the project. We made our plans for dissemination clear in advance and have been careful to maintain the anonymity of the settings and participants taking part in the study.

\section{What form does active learning take in P1? Evidence from five 'active learning' classrooms}

In this section we will present evidence from our observations in terms of three themes which allow us to build a cross-case picture of the form in which active learning was being put into practice in the participating classrooms. The three themes relate to observations of:

- the physical environment and learning resources deployed

- the classroom schedule of activities, teacher and child actions 
- children's engagement in the classroom.

This thematic presentation is offered here as a basis for considering how the guidance about active learning was interpreted in practice in particular settings.

\section{The environment and resources}

The ways in which teachers were able to use the space available and deploy additional adults to support learning activities suggested a planned rather than a spontaneous or responsive environment. In each case room for activities depended on space shared with other classes, requiring adherence to an agreed timetable. Where there was sufficient space some resources for individual or small group use were set out in the classroom. Elsewhere, tables and chairs took up most of the space so resources for activities were brought out of storage when the teacher directed.

Adults too are an important resource in early years learning environments. The number of adults present in each classroom varied across the day and week. At times the class teacher was supplemented by classroom assistants, nursery nurses, student teachers or parent helpers. When possible the teachers arranged for the periods when children were involved in activities in small groups to coincide with the availability of additional adults. The teachers planned the group activity and gave instructions about what the children were expected to do or how they were to use the resources, and in some cases gave a model 'end product' too. In Box 1 extracts from scan data illustrate the deployment of children, adults and resources.

\section{Box 1 about here}

\section{Daily schedules, Actions and Activities}

At no point in any of the classes we observed were children able to pursue an activity of their own choosing or one on offer in the classroom at a time of their own choosing. In contrast to the relative freedom to choose what to do and when to do it in preschool settings the timetable in P1 was adult-directed. In the course of each day children in every class experienced a mix of time gathered together as a whole class and other periods when they were distributed across the classroom and additional spaces in small groups. The proportion of time spent together as a class or distributed around a range of activities varied from class to class. Whole class gatherings ranged from several brief periods during the day to examples of spells of about an hour focused on one 'subject'. Typically children were gathered together for phonics tuition, to be introduced to or practice reading new words or be taught about a grammar rule or mathematical operation. Whole class sessions were also used to introduce the events of the day, discuss rules for behaviour and classroom routines and to listen to stories, as well as for specialist music, art, physical education and science lessons, where these were offered. Examples from the scan data of 'whole class' events are set out in Box 2.

\section{$\overline{B o x} 2$ about here}

During whole group sessions the evidence from our observations suggests that active learning was construed as involving physical movement, question and answer 
sessions with the teacher, the manipulation of physical resources (e.g. for counting or telling the time) or participating as an audience while others carried out some action in response to a request from the teacher (e.g. selecting the rhyming word from a selection on the board, ordering numbers). Phonics often involved the whole class responding all together or in turn to letters and words shown, 'sounding out', identifying letter and sound matches and clapping out syllables. Number work might involve children lining up to form a human 'number line', making a small toy jump along a ladder to add or subtract or responding to a mental arithmetic question by holding up the correct answer on a number fan.

\section{Box 3 about here}

Box 3 lists the categories of teacher and child actions observed during periods when the whole class was gathered together. These categories represent the behaviours typical for adults and young learners across the year and the five case study settings. We explored the data further by looking at the most frequently observed teacher behaviours within each case. Three categories of action dominated when teachers were interacting with the whole class:

- Teacher leads/directs activity - poses closed questions, selects respondents and sets tasks

- Teacher manages transition between activities and parts of the daily programme (e.g. greetings and departures); assists/records children choosing activities where allowed

- Teacher explains next task or new activities to whole class, gives instructions or information.

When they gathered the whole class together teachers focused on giving information and instructions and on managing children's behaviour and responses. In some cases it was possible for all the children to respond at the same time (e.g. by chanting the sounds of letters) but they were often required to wait quietly and attentively until invited to make an individual response. The three most frequently recorded categories of child actions during whole group sessions were

- Child responds one at a time, waits for turn, watches others respond

- Child listens and is not required to respond while teacher gives information, instructions, explains choices available, introduces new concepts

- Child shows signs of inattention, fidgeting, chatting, sitting with head on hands.

When the class was distributed into small groups they were involved in activities that were either (i) 'closed', with children working towards a correct answer, particular product or copying a model shown by the teacher (e.g. tracing letters in sand; arranging words into a sentence) or (ii) open with no 'right answer' and allowing more scope for individual responses (e.g. using small world resources or listening to a story tape). Box 4 contains examples from the scan data of the range of activities children experienced. 
The categories of teacher actions and child responses observed during small group time are given in Box 5.

\section{Box 5 about here}

Children's response modes were more varied during the periods when they were place in small groups to engage with specific activities than they were during 'whole class' periods but three categories of response were most frequently recorded:

- Child in group responds individually by writing, reading, doing arithmetic operations

- Child participates individually or with peers in directed/correct answer games or activities e.g. sorting \& sequencing, making a model like an example shown

- Child participates individually or with peers in open-ended activities e.g. using dough, playing in the imaginary hospital area.

Teachers too behaved somewhat differently during these periods, most notably taking advantage of the opportunity to spend time alongside children engaged in activities. As with the observations during 'whole class' periods, we identified the most frequently noted categories of teacher behaviour when the children were distributed in clusters. Four forms of action were predominant:

- Teacher alongside as children complete a task, scaffolding responses, guiding participation

- Teacher leads the group in activity, poses questions, checks responses, uses closed questions and answers

- Teacher oversees the room - reactive supervision

- Teacher manages the rotation of activities and movement of children to allocated groups.

\section{Children's engagement in active learning}

The evidence from the target child observations on levels of engagement reveals a picture of considerable fluctuation even within the five-minute observation episodes and of variability depending on the individual and the activity in which they are engaged. There were differences between children in their typical level of engagement. Some children were repeatedly noted as only passively engaged or disengaged while others were recorded as always at least intermittently engaged and more usually engaged or intensely engaged. However, even children whose characteristic level of engagement was passive or disengaged were occasionally observed to be intensely engaged in a particular task. For instance, our observations of one target child suggest that he was typically passively engaged and often disengaged. However, he was recorded as intensely engaged during one episode when he was involved in pasting words beneath a picture he had drawn. But moments of intense engagement were often fleeting because the task lasted only for a short period of time or children were required to move on to another activity. In the example above the pasting activity lasted less than five minutes. When it was completed the boy was asked to move on to a colouring task which he failed to complete correctly. Further examples of varying patterns of engagement within individual children are given in Box 6. 
No one task or form of interaction could be identified as more engaging than another for all children. The more open-ended activities where children interacted with peers at small world play, shared books or together searched for letters to build words or explore number bonds produced periods of engaged (though distractible) involvement and some examples of intense and sustained engagement. On the other hand, some children were observed to be engaged (sometimes intensely engaged) when alone painting or drawing, copying words, writing 'number stories', at construction or involved in imaginative play. Children were engaged (or intensely engaged) during whole class periods too, such as when the teacher read a story or led phonics and reading exercises, particularly when these were presented in a playful and competitive manner.

Levels of engagement typically dropped when children were required to wait for a turn (e.g. reading practice, word bingo) or listen to instructions or explanations. In other cases, children's engagement in an activity rose when there was a supportive adult (not necessarily a teacher) alongside but fell when there was no one to help or to remind the group about each stage of a task. Disengagement was most often observed during periods of transition or attention to routines such as ordering lunches or distributing materials to take home. However, some individuals typically became disengaged when the whole class was gathered and responding in turn or during periods when they were allocated to particular activities.

\section{Discussion: Problematising active learning in primary school}

This study set out to explore how teachers were implementing the policy imperative to move to active learning at the beginning of primary school. We wanted to know how teachers interpreted active learning in their everyday practices and to find out about the activities and interactions which children experienced in an active learning environment.

The evidence we gathered suggested that while there have been innovations in practice, these may perhaps best be described as changes in degree rather than revolutionary departures. Indeed, some of the practices we observed may happen in classrooms where there is no formal adherence to 'active learning' guidance. Nevertheless, for the participants in our study there had been a shift, of varying proportions, towards a culture of teaching which was open to alternative ways of learning and demonstrating learning and of enhanced reflection on 'what works' for children (Stephen, Ellis and Martlew, 2009). Although active learning was interpreted in individual ways by each teacher, and children's experiences depended on the class they attended, our observations suggested that in each of the five classes, there had been a move away from the dominance of pencil and paper as the response mode towards manipulating objects, physical actions and verbal responses.

Comparing the classroom interpretations of active learning which we observed with the characteristics set out in the policy guidance suggests that not all the expected components were present in these cases. There was evidence of what might be considered from the perspective of the teachers as 'planned, purposeful play' and of focused teaching but no evidence of spontaneous play and little evidence of responding to individual interests. Although there were 
occasional examples of teachers following up a discussion about a child's interest or a local event with a series of activities these were again planned and adult directed, at some distance in time from the initial stimulus and often used as the vehicle for an aspect of learning that was part of the adult's agenda. We saw few examples of learning using real-life or imaginary situations and the prevalence of closed activities where a 'right answer' was sought suggested that the opportunities for exploration and investigation were limited. Scheduling also imposed limitations: activities were planned by teachers and carefully timetabled. Children were usually directed to activities and in the one case where there was an element of choice about what to do on any one day they were required to take part in the full-range over the course of a week. In all classes children were expected to begin and finish an activity in line with the teacher's timetable and there was little scope for flexibility in pace.

These findings raised a number of questions about what is presented in Scottish policy and practice guidance as the preferred pedagogy for children in the early years, including those in the first year of primary school. Our first question concerns the nature of active learning, action and activities. In each class children spent varying amounts of time in what were referred to as 'activities' and it seems that in these cases spending time distributed in small groups around the classroom was an important part of the way in which the teachers interpreted active learning. This had implications for children but also made an important difference to teachers as it enhanced their opportunities to be alongside children, modelling an action or extending thinking and benefiting from periods of sustained, shared thinking (Siraj-Blatchford et al, 2004). But these kinds of interactions were infrequent from the perspective of an individual child who, even when taking part in a group activity, often had to wait for a turn or for attention from an adult.

Extending the range of modes of response or engagement available for children beyond the more traditional 'table top' and 'pencil and paper' actions is the second most obvious change to have come about with the move to active learning. Building a model, writing in foam, fishing for letters to form words or sorting socks into pairs according to given characteristics were all ways of demonstrating or practicing their learning available to children in the classes observed. However, these activities were arranged by adults to achieve specific learning outcomes and, for the most part, children were directed to engage with the activity at specified times and for timetabled periods.

The observed activities did not arise from the children's everyday experiences, particular interests or behaviours in play and even those which did involve authentic resources took on a distinct 'educational' form in the classroom. For this reason questions remain about the extent to which the interpretations of active learning which we observed offered opportunities for the 'meaningful' engagement in learning which the approach is said to offer. We did not see children attempting to solve problems which they had identified or to achieve goals negotiated with peers and adults. If active learning is defined as engagement in learning that is personally rewarding for the learner then questions arise about whether what we observed in the P1 classes was indeed active learning. But incorporating even a degree of such an individual and childdriven approach remains a considerable challenge in the educational culture typically encountered in primary schools.

The construction of learning as what happens in the process of interacting with material resources and other people appears to be over-shadowed in school by 
attention to expectations about progress towards specific targets such as those for reading or number work. When children and teachers are assessed against particular outcomes it is difficult to see how practice that focuses on the kind of learning evidenced in performance and participation will flourish. Compared to the primary school environment, learning in the preschool playroom can be more responsive to individual children's interests and needs. Although the activities and resources in the playroom are supplied by adults, the children are able to choose when to engage with specific activities and the equipment and tasks are much more likely to afford open-ended play or exploration. However, implementing these practices in Scottish $\mathrm{P} 1$ classrooms requires a shift in thinking about pedagogy and educational outcomes that goes beyond the bounds of individual teachers and their interactions with the children.

We recorded only one instance of a teacher following up a child's 'line of flight', taking the learning for a group in an unplanned direction in response to a question (Taguchi, 2010). Opportunities to act in this way are clearly constrained by the teacher's perception of her role and responsibilities. The teachers taking part in this study were careful to provide some opportunities, usually in the whole class group, for children to be introduced to strategies to support learning and think about what they were doing and why. Children were asked to recall what they knew or had been exposed to and to practise rules and newly acquired strategies. But there was no evidence of spontaneous or systematic reflection on what had been learned during open-ended activities and only a minority of the activities experienced each day were reviewed with an adult. Activities such as play in the imaginative area, painting or small world play may afford less explicit challenges or prompts to reflect, question or problem-solve and we saw no instances of discussion of these activities with the whole class or targeted groups of children. Designing tasks or activities to sustain a child's engagement, scaffold her actions and prompt cognitive reflection, especially in the absence of an adult, is a demanding role for teachers and not one that is, as yet, explicitly addressed in the training or guidance available to them.

Although some of the teachers were keen to stress that their new practices had enhanced the cohesion of the class and that children knew they could seek help from each other, there was little evidence of activities being designed to require the co-operative or collaborative learning to achieve a goal or create a product that is sometimes considered a feature of active learning. Our observations suggest that children were much more likely to be working in parallel on similar tasks, using shared resources or, during whole class sessions, observing another child responding. Our questions about the children's level of engagement during particular activities in small groups or with the whole class, especially when they were required to wait for a turn or watch others answering or acting, were typically met by teachers with assurances that the children who were waiting were thinking about what they were observing. While it is clear that involvement in active learning does not require physical activity our observations suggest varying levels of engagement for children across the day and, in specific instances, we noted that some individuals were engaged only intermittent or passively or even repeatedly disengaged. Meeting the needs of all learners in a class is a demanding feat for any teacher and it seems important to recognise that moving to an active learning pedagogy (as constructed in this study) does not remove this challenge.

In their accounts of the changes in their practices the teachers talked about there being 'more than one way to learn'. However, they did not make explicit 
references to their own understanding of how children learn and there was no evidence in discussions with them of any recourse to theory or empirical evidence other than their own experiences. While this may not be surprising from those whose focus is on practice, it appeared that the practice guidance and training undertaken had not equipped the teachers with a rationale for the conditions for learning they were implementing. This lack of discussion about the process of learning and the pedagogic function of the adult in creating conditions that facilitate learning can leave teachers ill-equipped to make thoughtful, professional judgements about innovations in practice and the nature of their role. It risks teachers adopting a technical approach, putting into practice a formulation based on particular activities or daily routines: an approach which inhibits professional development and the application of nuanced decision-making that is sensitive to the needs of individuals and the context in which they learn. Changing pedagogy involves not only changing practices but thinking differently about the process of learning and the role of the learner and teacher.

\section{Acknowledgements}

Our observations of active learning as it was implemented in the first class in primary school were conducted as part of the Applied Educational Research Scheme (AERS), which ran in Scotland from $2004-2009$.

\section{References}

Alexander, R. (ed.) 2009. Children, their World, their Education. Final report and recommendations of the Cambridge Primary Review. Abingdon: Routledge.

Bennet, N., Wood, L. and Rodgers, S. 1997. Teaching Through Play Teachers' thinking and classroom practice. Buckingham: Open University Press.

Bredekamp, S. and Copple, C.1997. Developmentally Appropriate Practice in Early Childhood Programs (Revised Edition). Washington:National Association for the Education of Young Children.

Department for Children, Schools and Families (DCSF). 2009 Independent Review of the Primary Curriculum (Rose Report). Nottingham: DCSF Publications. Available online at:

http://publications.teachernet.gov.uk/default.aspx?PageFunction=productdetails\&Pag eMode=publications\&Productld=DCSF-00499-2009 accessed. 11 May 2010.

Department for Children, Schools and Families (DCSF). 2007. Early Years

Foundation Stage Effective Practice: Active Learning- In Depth. Available online at: http://nationalstrategies.standards.dcsf.gov.uk/node/84341?uc=force uj accessed, 11 May 2010.

Donaldson, M. 1978. Children's Minds. London: Fontana.

Fleer, M., Tonyan, H.A.,Mantilla A.C. and Rivalland, C.M.P. 2009. A CulturalHistorical Analysis of Play as an Activity Setting in Early Childhood Education. In Childhood Studies and the Impact of Globalization: Policies and Practices at Global and Local Levels, ed. M. Fleer, M. Hedegaard and J Tudge. 292-312. New York: Routledge. 
Hedegaard, M. and Fleer, M. 2008. Studying Children: A Cultural-Historical Approach. Maidenhead: Open University Press.

Hohmann, M, and Weikart, D. P. 1995. Educating Young Children, a curriculum guide from High/Scope Educational Research Foundation. Ypsilant: High/Scope Press.

Isaacs, S. 1932. The Nursery Years The Mind of the Child from Birth to Six Years. London: Routledge and Kegan Paul.

Montessori, M. 1966. The Secret of Childhood. New York: Ballantine Books.

Learning and Teaching Scotland. 2009a. Curriculum for Excellence. Available online at:

http://www.Itscotland.org.uk/curriculumforexcellence/curriculumoverview/index.asp accessed 11 May 2010.

Learning and Teaching Scotland. 2009b. Sharing practice - Approaches to learning Active learning. Available online at:

http://www.Itscotland.org.uk/earlyyears/sharingpractice/approachestolearning/learnin gthroughplay/index.asp accessed 11 May, 2010.

National Association for the Education of Young Children (naeyc). 2009.

Developmentally Appropriate Practice in Early Childhood Programs Serving Children from Birth through Age 8. Available online at: http://www.naeyc.org/DAP accessed 11 May 2010.

Northern Ireland Curriculum. 2009. Understanding the Foundation Stage. Available online at: http://www.nicurriculum.org.uk/foundation stage/

accessed 11 May, 2010.

Olsson, L.M. 2009. Movement and Experimentation in Young Children's Learning. Abingdon and New York: Routledge.

Rogoff, B. 2003. The Cultural Nature of Human Development. New York: Oxford University Press.

Schaffer, H. R. 2004. Introducing Child Psychology. Oxford: Blackwell Publishing.

Scottish Executive. 2007. A curriculum for excellence-building the curriculum 2active learning in the early years. Available online at http://www.Itscotland.org.uk/curriculumforexcellence/buildingthecurriculum/guidance/ btc2/index.asp accessed 11 May 2010.

Siraj-Blatchford, I. 1999. Early Childhood Pedagogy: Practice, Principles and Research. In Understanding Pedagogy and its Impact on Learning, ed. P. Mortimer, 20-45. London: Paul Chapman Publishing Ltd.

Siraj-Blatchford, I. and Sylva, K. 2004. Researching pedagogy in English preschools. British Educational Research Journal 30, no 5: 713 - 730.

Stephen, C. 2006. Early Years Education: Perspectives from a review of the international literature. Scottish Executive Education Department. Available online at http://www.scotland.gov.uk/Publications/2006/02/06145130/0

accessed 11 May, 2010. 
Stephen, C. 2003. What makes All-day Provision Satisfactory for 3- and 4-Year Olds? Early Child Development and Care 173 no 6: 577-588.

Stephen, C. and Cope, P, 2003. An Inclusive Perspective on Transition to Primary School. European Educational Research Journal, 2 no 2: 262-276.

Stephen, C., Cope P., Oberski I. and Shand, P. 2008 'They should try to find out what the children like': Exploring Engagement in Learning. Scottish Educational Review 40 no 2: 17-28.

Stephen, C., Ellis, J. and Martlew, J. 2009. Turned on to Learning 2: Active Learning in Primary One. Applied Educational Research Scheme, Research Briefing 8. Available online at http://www.ioe.stir.ac.uk/staff/stephen.php accessed on 11 May 2010.

Taguchi, H. L. 2010. Going Beyond the Theory/Practice Divide in Early Childhood Education. Abingdon and New York: Routledge.

Teachernet. 2007. Learning and development: Active learning. Available online at http://nationalstrategies.standards.dcsf.gov.uk/search/earlyyears/results/nav:46388 accessed 11 May 2010.

Welsh Assembly Government. 2008. Play/Active Learning - Overview for 3 to 7-year olds. Available online at http://new.wales.gov.uk/topics/educationandskills/policy strategy and planning/1040 $\underline{09-}$ wag/foundation phase/foundationphasepractitioners/playactive/;jsessionid=LGk4LC WSfJprnyxLg2PqHIcT2Vbp1l6T8thwQTGHJSgQvQq4N1yp!686978193?lang=en\&ts= 1 accessed 11 May 2010.

Vygotsky, L. 2004. Imagination and Creativity in Childhood. Journal of Russian and East European Psychology 42, no1: 7-97. (translated by Sharpe, M.E. from Russian text, 1967).

Wertsch, J. V. 1998. Mind as Action. New York: Oxford University Press. 
Box 1: Activity time: tasks, resources and adult support

\subsection{0 am 23 Nov.}

Victoria Primary - children dispersed to 4 activity areas

5 children at imaginative area set up as science lab. Each has bowl of 'gloop', encouraged to explore consistency etc. by teacher alongside for some of the activity period

9 children engaged in table top activities (i) colouring in 'safe to eat' items on a worksheet (ii) exploring bending, twisting and cutting a range of materials and recording the results.

Teacher explains task and nursery nurse supervises

4 children play with Brio train set on the floor - nursery nurse supervising table top activities casts an eye over play.

\subsection{0 am 24 April}

Holy Family - children at activities in classroom and 'open area'

2 children play with dolls house - unaccompanied

4 children play with train set - unaccompanied

4 children play board game with classroom assistant

2 children use play dough with parent helper

4 children use sand - unaccompanied

2 children use pre-loaded games on the computer - unaccompanied

3 children at writing activity with teacher

Box 2: Whole class learning activities

\section{$11.4018 \mathrm{Dec}$}

St Roch Primary - 23 children in whole group, sitting on floor in front of teacher. Teacher uses white board to revise 'hard words' (words that cannot be approached phonetically), using question and answer with children. 1 child disengaged does not look at words, 3 children passive - do not offer any responses.

\subsection{0 $1 \mathrm{Nov}$}

Holy Family -25 children in whole group with teacher. Children all sitting at tables. Teacher selects children in turn to 'make 5' - e.g. clap 5 times, nod 5 times. Children watch and wait for a turn then act when selected. All engaged. 
Box 3 Teacher and child actions during whole class sessions

\begin{tabular}{|c|c|}
\hline Teacher actions - whole class periods & Child actions - whole class periods \\
\hline $\begin{array}{l}\text { - } \text { Manage and explain class schedule } \\
\text { - } \text { Manage behaviour } \\
\text { - } \text { Instruct children's actions } \\
\text { - } \text { Praise } \\
\text { - } \\
\text { - } \text { Sead discussions } \\
\text { Ask questions }\end{array}$ & $\begin{array}{l}\text { - Listen, look, chant responses, give } \\
\text { - } \quad \text { Asswers } \\
\text { - } \quad \text { Count, add, measure, make number } \\
\text { stories } \\
\text { - } \quad \text { Identify words, letters, sound and } \\
\text { rhymes } \\
\text { - Respond to behaviour rules } \\
\text { - } \quad \text { Rehearse tasks/skills } \\
\text { - Use Smartboard }\end{array}$ \\
\hline
\end{tabular}

Box 4 Small group learning activities

\subsection{June}

South Side 1-23 children distributed over activities in shared area. Activities: listening to story through headphones at listening post; water trough; reading in book corner; writing table; small world (air travel); construction; painting; playing in shop

\subsection{June}

South Side 2-21 children distributed over activities in classroom.

Activities: number games on computer; using roamers; listening to story through headphones at listening post; playing letter 'hangman'; writing table; playing snakes and ladders; writing number stories on white boards; doing sample number work supervised by teacher.

Box 5 Teacher and child actions during small group activity periods

\begin{tabular}{|c|c|}
\hline Teacher actions - small group time & Child actions - small group time \\
\hline $\begin{array}{ll}\text { - } & \text { Manage schedule and activity } \\
& \text { change over } \\
\text { - } & \text { Explain activity } \\
\text { - } & \text { Manage behaviour } \\
\text { - } & \text { Direct children's actions } \\
\text { - } & \text { Instruct small groups } \\
\text { - } & \text { Encourage } \\
\text { - } & \text { Scaffold actions } \\
\text { - } & \text { Evaluate actions/written work }\end{array}$ & $\begin{array}{l}\text { - } \quad \text { Follow instructions } \\
\text { - } \quad \text { Negotiate roles with others } \\
\text { - } \quad \text { Order words/numbers } \\
\text { - } \quad \text { Copy patterns/draw pictures } \\
\text { - } \quad \text { Listen to stories or songs } \\
\text { - } \quad \text { Practise reading } \\
\text { - } \quad \text { Give answers } \\
\text { - } \quad \text { Measure, count, add up } \\
\text { - Line up, clear up, move round } \\
\text { - } \quad \text { o puzzles, build }\end{array}$ \\
\hline
\end{tabular}




\section{Box 6 Children's engagement in classroom learning opportunities}

\begin{tabular}{|c|c|}
\hline $\begin{array}{l}20 \text { June - Anna South Side } 2 \\
9.24 \text { Anna waiting at table while teacher } \\
\text { distributes tasks. Her group given a word- } \\
\text { building puzzle. Anna leans on the table and } \\
\text { looks around as Jane throws the dice. } \\
\text { Teacher comes to group to explain how to } \\
\text { start the game. Jane throws the dice again } \\
\text { and hands Anna a letter. Anna does not react } \\
\text { or recognise that this is her turn. Group fail to } \\
\text { build any words - Anna disengaged } \\
\text { throughout the activity. } \\
10.05 \text { In the shared activity area outside the } \\
\text { classroom Anna and Mhairi are listening to a } \\
\text { story tape. Both girls laugh as they listen and } \\
\text { agree to return tape to beginning of story as } \\
\text { they discuss events narrated. Anna says 'Oh } \\
\text { I like this' and draws Mhairi's attention to a } \\
\text { picture. She dances as music plays on the } \\
\text { tape and sings out the animal sounds. } \\
\text { Anna engaged (but distractible) throughout } \\
\text { episode. } \\
11.13 \text { Whole class gathered for science with } \\
\text { visiting teacher. Anna smiles as the music } \\
\text { plays but does not join in with others } \\
\text { clapping. She laughs at the behaviour of } \\
\text { another child. The teacher asks the children } \\
\text { to vote for their preferences but Anna does } \\
\text { not take part - she looks around as others } \\
\text { vote but remains passive. }\end{array}$ & $\begin{array}{l}1 \text { November-Dan Holy Family } \\
11.08 \text { Dan is in small group with nursery } \\
\text { nurse for reading practice. As adult reads he } \\
\text { looks at his book, turns the pages and looks } \\
\text { around the room. He is not asked to read and } \\
\text { does not join in when others chat. Passive. } \\
11.50 \text { Whole class gathered on carpet and } \\
\text { asked to sit nicely. Dan sits very still and } \\
\text { looks at the teacher as she introduces activity } \\
\text { on the Smartboard. Dan then sits with his } \\
\text { head on his hands as other children make } \\
\text { suggestions. He watches one child respond } \\
\text { on the Smartboard, sitting very still and } \\
\text { looking intently at the screen. He is chosen to } \\
\text { find a word on the screen and does it } \\
\text { correctly. Teacher helps him to press button } \\
\text { to get a well done message. Dan returns to } \\
\text { his place and looks back at the screen. } \\
\text { Intermittent engagement. } \\
\text { 12.20 Children gathered to hear introduction } \\
\text { to a number activity to be completed on a } \\
\text { worksheet. Enlargement of worksheet is on } \\
\text { screen as teacher goes through examples. } \\
\text { Dan sits still but remains passive throughout. }\end{array}$ \\
\hline
\end{tabular}

